\title{
Importance of digital annual reports
}

\author{
F. Haasbroek \\ Gold Fields Library and Information Centre \\ Technikon SA \\ fhaasbro@tsa.ac.za
}

\section{A.S.A. du Toit}

Department of Information Studies

Rand Afrikaans University

asadt@rau.ac.za

\section{Contents}

1. Evolutionary stages of annual reports on the Internet

2. Digital format of annual reports on the Internet

3. Benefits of annual reports on the Web for stakeholders and companies

4. Annual reports via the Web in South Africa

5. Conclusion

6. References

\section{Evolutionary stages of annual reports on the Internet}

The on-line annual report is usually located on the corporate Web site under the investor relations section, company information section or financial information section (Petravick 1999:36).

Annual reports are undergoing a profound transformation on the Web. The boundaries of Web-based annual reports are dynamic and becoming less distinct, giving the user many viewing options and formats. The transformation is a result of companies increasingly serving the business needs of virtual global communities.

Hedlin (1999:373) identifies three distinct evolutionary stages in the development of an annual report on corporate Web sites. These are summarized below.

\section{1 Stage one: establishing a Web presence (early)}

The first generation of Web sites contained general company information of little interest to investors. These Web sites did not communicate with a particular audience or purpose. Most Web sites focused on the customer and not on the investor. Some Web sites had a form where a paper version of the annual report could be ordered. 


\section{2 Stage two: use of the Internet to publish annual reports (intermediate)}

This stage was characterized by an assessment of the different needs of various groups with which the company wished to communicate. Electronic versions of paper-based annual reports were added to corporate home pages. The Web was seen as an efficient and low-cost distribution medium for information, but little attention was paid to unique advantages of the Internet, which could facilitate innovation in digital annual report presentation.

\section{3 Stage three: full usage of the visually exciting and multimedia capabilities of the Internet in electronic annual reports (advanced)}

In this stage the unique, rich features and possibilities of this interactive medium are taken advantage of, for example slide presentations, animation, music, streaming audio and video.

\section{Digital format of annual reports on the Internet}

Companies present annual reports on the Internet in the following on-line formats:

- Portable document format (PDF): a special file format developed by Adobe Corporation for creating documents that are exact representations of the original printed documents. All elements of a printed document are captured as an electronic image. PDFs are independent formats, written by Adobe Acrobat software, that retain the original fonts, colours, formatting and images on multiple computer platforms. Adobe Acrobat Reader is required to view, navigate and print a PDF document. The software is downloadable from Adobe Systems (http://www.acrobat.com) at no charge. It is possible to view and print PDF documents with certain Internet browsers by using a plug-in (Conosco 1999:58).

- Hypertext markup language (HTML): the programming language of the Web. This is the common standard to present information on the Internet and create Web pages. HTML commands are used to build Web pages that can display text and graphics (Conosco 1999:55).

- Graphics interchange format (GIF): a file format for graphics that compresses images without losing any information, readable by most browsers and the usual format on the Web. It works best with images containing solid blocks of colour. Images can be animated (Conosco 1999:55).

- Joint photographic expert group (JPEG): a graphic format used for compressing photographic images down to a reasonable size for use on the Web (Conosco 1999:56).

- Microsoft Excel spreadsheet: a computer application program that simulates a physical spreadsheet by capturing, displaying and manipulating data arranged in rows and columns. In a spreadsheet, spaces that hold items of data are called cells. Each cell is labelled according to its placement (for example A1, A2, A3) and may have an absolute or relative reference to the cells around it. A spreadsheet is generally designed to hold numerical data and short text strings. Spreadsheets usually provide the ability to portray data relationships graphically. Lotus 1-2-3 and Microsoft Excel are the most popular.

- Microsoft Word: the most widely used word processing application.

- Zip files: WinZip is a Windows program that allows users to archive and compress files so that they can be stored or distributed more efficiently. WinZip has a simple drag-and-drop interface that allows the user to view individual files in a zip file without unzipping the file. WinZip also launches installation programs from a zip file and automatically clean up after the installation. 
- Macromedia Flash software: the standard for delivering high-impact, lightweight Web content. Designs, animations and application user interfaces are deployed immediately across all browsers and platforms, attracting and engaging users with a rewarding Web experience.

- RealNetworks RealPlayer software: the most common plug-in that enables streaming audio and video.

- Macromedia Shockwave software: this software is a family of multimedia layers. Web users can download the Shockwave players from the Macromedia site and use them to display and hear Shockwave files.

\section{Benefits of annual reports on the Web for stakeholders and companies}

There has been a dramatic increase in the percentage of annual reports on-line due to the following benefits:

\section{1 Benefits for stakeholders}

\subsubsection{Up-to-date information}

The key advantage of on-line communication is instant access and availability of up-to-date information. Usually investors will look at the company Web site for the information before contacting a company directly. Previously, annual reports were perceived as historical documents for the archives (Rhein 2000:73).

\subsubsection{Timeliness}

The Web enables users to retrieve and receive information the moment it is published and increases the timeliness of information provided. The information is easy to access for all user groups.

\subsubsection{Free information in greater volumes}

There is tremendous growth in the number of third party Web sites and on-line investment brokers assemble financial and other business information related to companies. Third parties are gathering information and adding value to it. These sites enable investors to save time and effort searching the Internet by collecting the data and providing access through a single site. These Web sites give visitors the capability to search a variety of sources for information on a particular company or industry. Enhanced search, download and data formatting capabilities are also provided. The downside for investors is that most of the information is available only through subscription or direct purchase. Some information may be provided at no charge. Web sites often require users to register and data can only be accessed with a password. The benefit of annual reports on company Web sites is that the information is free. Freely available and easily accessible company information sources are usually widely used.

\subsubsection{Information to support decision making}

Information provided on a corporate Web site should provide investors with all relevant information required to make informed risk assessment and investment decisions. In certain instances, information about a company can be found only on the Web (LaRose 1997:32).

\subsubsection{Depth and context}

Individual investors can access information according to the depth, level of detail and technicality of the information that they need. This can be an interactive communication with stakeholders who are able to be highly selective about the information accessed, drilling down to more in-depth information that is not possible in paper-based reports. 


\subsubsection{Access on demand}

Investors can instantly access and retrieve information on-line in their own time and in any time zone anywhere in the world. The Internet is a 24-hour 365-day a year medium. The annual report is an easy, fast and worldwide access point to company data. The importance a company places on the accessibility of annual reports and financial information can be measured by how deep (levels down from the home page) the material is placed on the Web site. The deeper it is in the site, the harder it is to find and therefore the lower the priority the data are likely to receive in the design of the site (Lymer and Tallberg 1997).

Users can be immediately gratified by going directly to the annual report site instead of waiting for the report to arrive in the mail.

\subsubsection{Cost}

The cost for users to access annual reports on-line is low. Shareholders can receive information on-line instead of attending annual meetings. This saves on travelling costs.

\subsubsection{Investor empowerment}

Large institutional investors routinely have the opportunity for private meetings with management to gather information. Previously the smaller private investors were distanced from contact with management and had to rely almost exclusively on professional advisors for information. Now shareholders are empowered because the barriers to accessing information are significantly lowered (Amernic 1998).

\subsubsection{Unfiltered information}

Investors prefer information straight from the 'horse's mouth', devoid of inaccuracies. They may perceive intermediaries, such as brokers, as less trustworthy in this regard. Investors can retrieve the facts from third party financial Web sites, but they can only get the 'real story' from the company annual report (print or on-line).

\subsubsection{Historical information}

Some companies offer a Web archive of annual reports with a back file of two to five years. This is useful for the user who wishes to analyse the progress of the company. The corporate Web site should serve as repositories for the most current report and reports of several previous years (Toronto Stock Exchange 1999:2). This eliminates the need for libraries and other corporate information centres to store annual report collections. It saves space and the labour of ordering and filing it.

\subsubsection{Hyperlinks to other information}

Hyperlinks improve the readability of annual reports and user access to information. Some Web sites provide the user with links to additional information. Hyperlinks give users the illusion of more control over the information accessed. The Internet user can choose which link to follow through the corporate annual report portion of the Web site.

\subsubsection{Personalization and customization}

Information can be customized and personalized to take account of the needs of individual stakeholder groups (possible through the use of intelligent agent software). Information can be filtered, prioritized and annotated to meet the criteria of the users. Customized e-mail allows investors to receive alerts and information of interest, for example newsletters and press releases.

\subsubsection{Global reach}

The Web has the ability to reach an international global audience. On the Internet the company can present corporate financial data in accordance with the accounting standards, languages and currencies of multiple countries. The Web offers the ability to rapidly or 
instantly update facilities to enhance the provision of performance data.

\subsection{Single point of reference}

An annual report is a comprehensive source of information of activities of a company. Very often it provides information that a user cannot locate from any other published source. Once bookmarked on a user's Internet browser, the information is easy to locate.

\subsubsection{Downloading and manipulation of data}

Companies can present corporate information in spreadsheet format. Data can be downloaded or exported for user manipulation and analysis.

\subsubsection{Search facility}

Effective internal search tools within Web sites can help users to find relevant information. Users can search the contents of HTML and PDF annual reports, using keywords for specific data. Previously, the user had to read extensive amounts of text to extract a specific piece of information. Companies should provide a sophisticated internal site search facility that makes it easy for investors to find information.

\subsubsection{Preventing information overload}

Internet technology means that more information and more sources of information about a company are available. The overabundance of information results in information overload. Internet users are not equipped to handle information glut or judge the quality and validity of what they access on third party Web sites. The corporate Web site and annual reports should be the most complete source of information and first choice of the corporate information seeker. The Web site should provide timely and precisely targeted business information.

\subsection{Benefits for companies}

\subsubsection{Effective communication}

The Web is an effective way to communicate with potential investors and shareholders. Companies can communicate with previously unidentified information users. It is a medium for dialogue with stakeholders that can be designed to encourage them to provide feedback to the company. The Internet provides a broadcast (mass communications) medium for corporate reports.

\subsubsection{Site monitoring}

Companies can monitor and track the total activity of the investor relations section of Web sites to identify ways to improve site efficiency and increase usage. The data collected indicate how many people have accessed the annual report as well as the usefulness of the different types of information included on the Web. The data needs of stakeholders can be identified in this way (Financial Accounting Standards Board 2000; O’Kelly 2000).

\subsubsection{Global audience}

Companies are increasingly seeking markets beyond their borders. Digital annual reports provide unrestricted global access and increase the disclosure audience of a firm. It is an opportunity to enhance and expand the traditional information channels. The Web opens up readership to a much wider international audience (Russell 2000). Besides shareholders and other stakeholders, the 'public domain' in general can also take advantage of access to Webbased corporate information. Digital annual reports maximize the exposure of the annual report and increase the potential readers.

\subsubsection{Dynamic updating potential}

Regular maintenance of Web sites means that the information provided can be continuously updated to reflect new information, whereas paper reports have a very short shelf life. 
Outdated material can be removed promptly or moved to the archive section of the Web site.

\subsubsection{Interactivity}

A company can ensure maximum attention from on-line investors and be in a position to expand the business by making an interactive, visually appealing, on-line edition of the annual report available on its Web site. By doing this, the user-friendliness of the information is improved (Clackworthy 2000:38).

Multimedia enhances hypertext by adding animation, graphics, video and audio (Koreto 1997). The Internet can integrally accommodate interactive, non-linear, multimedia and animation elements. The on-line annual report becomes an experience that is simply not possible with the limitations presented by print media. The interactive nature of the Web will be an incentive for visitors to return to the Web site and will increase its 'stickiness'. The company can build strong ties with all stakeholders (Lehrer 2000:87).

\subsubsection{Hyperlinking}

Hyperlinks offer firms the opportunity to integrate several sections of the annual report and link financial disclosures to other pertinent information elsewhere on the Web site.

Companies can hyperlink to on-line stock prices and various additional information sources.

\subsubsection{Limitless space available}

Computer memory is cheap and a Web site offers almost unlimited space. More information can be added to a site to explain company performance. There are fewer constraints on presentation flexibility than with traditional paper versions.

\section{Annual reports via the Web in South Africa}

Nationally and internationally, there seems to be a definite increase in the use of the Internet as a platform for the presentation of electronic corporate report information. South Africa has made considerable progress in the virtual environment since 1999, with a dramatic increase in companies with a Web presence and digital annual reports.

In June 1999, the top 100 South African companies, ranked according to sales on the Business Times Web site (http://www.btimes.co.za), were examined. Only 38\% of the companies surveyed had no Web site. Table 1 shows that out of the 100 companies, $62 \%$ had a Web site. However, Table 2 indicates that only $11 \%$ of the surveyed companies had full annual reports available on-line (Stainbank 2000).

Table 1 Top South African companies on the Web in June 1999 (Stainbank 2000:23)

\begin{tabular}{|l|c|}
\hline & Number of companies \\
\hline Financial information on Web site & 33 \\
\hline No financial information given & 10 \\
\hline No Web site & 38 \\
\hline Failed to access & 18 \\
\hline Under construction & 1 \\
\hline Total & 100 \\
\hline
\end{tabular}

Table 2 Financial disclosures on the Web in June 1999 (Stainbank 2000:23) 


\begin{tabular}{|l|c|} 
& Number of companies \\
\hline Full annual report & 11 \\
\hline Financial statements & 22 \\
\hline Total & 33 \\
\hline
\end{tabular}

No South African research could be found after the 1999 Stainbank study and the authors of this article conducted a survey in May 2001 to establish what the current situation in South Africa is. Research indicated a dramatic growth in South African companies with Web sites since 1999. The top (industrial) companies (ranked by total assets) of the Financial Mail (Financial Mail 2000) was used to select the companies. Eight of the top 100 companies listed in the millennium edition of the Financial Mail were no longer listed on the JSE. To overcome this problem, the companies ranked 1-108 were selected. The 13 companies with no Web sites were phoned by the researchers to confirm that no Web site existed. The study failed to access three company Web sites, because the servers or networks were down and the Web sites were not available.

Table 3 illustrates that $87 \%$ of the top South African companies had Web sites in May 2001 compared to $62 \%$ in June 1999. The latest international study done in 2000 by the Financial Accounting Standards Board (FASB) indicated that 99\% of companies had Web sites. The number of South African companies with Web sites (87\%) was considerably less than the top international companies with Web sites (99\%). This indicates that South African companies were behind overseas companies in adopting the Internet as a delivery and communication mechanism.

Table 3 Top South African companies on the Web in May 2001

\begin{tabular}{|l|c|c|}
\hline & Number of companies & $\%$ \\
\hline Web site & 87 & 87 \\
\hline No Web site & 13 & 13 \\
\hline Total & 100 & 100 \\
\hline
\end{tabular}

According to Stainbank (2000), only 11\% of the top South African companies had full annual reports on the Web. Table 4 illustrates the findings of the present authors' survey conducted in May 2001. According to these statistics 53\% of the top 100 South African had full annual reports on the Web.

Table 4 Top 100 South African companies with full annual reports on the Web in May 2001

\begin{tabular}{|l|c|c|}
\hline & Number of companies & $\%$ \\
\hline Full annual report & 53 & 53 \\
\hline No annual report & 31 & 31 \\
\hline No Web site & 13 & 13 \\
\hline Failed to access & 3 & 3 \\
\hline Total & 100 & 100 \\
\hline
\end{tabular}

Tables 5 and 6 indicate that South African companies are moving from HTML format (16\%) to PDF format (37\%). PDF seems to be the most popular format at this time. Although only $16 \%$ of South African companies are using HTML format for presenting annual reports, the FASB study (FASB 2000) indicates that 59\% of the top 100 Fortune companies do so. 
Table 5 Annual reports in PDF only

\begin{tabular}{|l|c|c|c|}
\hline & 2000 Annual report & 1999 Annual report & 1998 Annual report \\
\hline Yes & $37(37 \%)$ & $19(19 \%)$ & $6(6 \%)$ \\
\hline No & $47(47 \%)$ & $65(65 \%)$ & $78(78 \%)$ \\
\hline No Web site & $13(13 \%)$ & $13(13 \%)$ & $13(13 \%)$ \\
\hline Failed to access & $3(3 \%)$ & $3(3 \%)$ & $3(3 \%)$ \\
\hline Total & 100 & 100 & 100 \\
\hline
\end{tabular}

Table 6 Annual reports in HTML only

\begin{tabular}{|l|c|c|c|}
\hline & 2000 Annual report & 1999 Annual report & 1998 Annual report \\
\hline Yes & $16(16 \%)$ & $19(19 \%)$ & $4(4 \%)$ \\
\hline No & $68(68 \%)$ & $65(65 \%)$ & $80(80 \%)$ \\
\hline No Web site & $13(13 \%)$ & $13(13 \%)$ & $13(13 \%)$ \\
\hline Failed to access & $3(3 \%)$ & $3(3 \%)$ & $3(3 \%)$ \\
\hline Total & 100 & 100 & 100 \\
\hline
\end{tabular}

Annual reports in PDF are usually broken down into subdivisions to facilitate ease of downloading. The study conducted by the FASB in 2000 on Fortune 100 companies indicated that $61 \%$ had annual reports exclusively in PDF format.

Companies also have historical, retrospective information on sites. Some companies offer full digital annual reports as far back as 1997. This is very useful for investors and analysts who want to follow the progress of the company.

Table 7 illustrates that only 2\% of companies in South Africa provide visitors the option of viewing the annual report in HTML or PDF format, compared to the 27\% Fortune 100 companies as reported by the FASB study.

Table 7 Annual reports in PDF and HTML

\begin{tabular}{|l|c|c|}
\hline & 2000 Annual report & 1999 Annual report \\
\hline Yes & $2(2 \%)$ & $4(4 \%)$ \\
\hline No & $82(82 \%)$ & $80(80 \%)$ \\
\hline No Web site & $13(13 \%)$ & $13(13 \%)$ \\
\hline Failed to access & $3(3 \%)$ & $3(3 \%)$ \\
\hline Total & 100 & 100 \\
\hline
\end{tabular}

Table 8 shows that only two companies (2\%) provided financial information in downloadable spreadsheet format, compared to the $16 \%$ Fortune 100 companies, as reported by the FASB study.

Table 8 Exporting of financial information to a spreadsheet

\begin{tabular}{|l|c|c|}
\hline & Number of companies & $\%$ \\
\hline Yes & 2 & 2 \\
\hline No & 98 & 98 \\
\hline
\end{tabular}


PDF is the most popular format for publishing annual reports on the Web (see Table 5). The PDF format is ideal for printing and the spreadsheet format for the manipulation of data. However, few South African companies currently use the corporate Web site as an electronic data archive to store historical corporate information. Ideally full annual reports for five years should be in PDF format and full financials should be available in spreadsheet format for downloading.

$\longrightarrow$ top

\section{Conclusion}

Transparency, openness, availability and accessibility of information are beneficial to learning, knowledge and the evolution of both individuals and the business environment. Internet technology is making markets more transparent and companies more open and accountable, resulting in increased shareholder loyalty and commitment.

South African companies are behind the top performing overseas companies in using the Internet as a delivery and communication mechanism to voluntarily disclose information and disseminate digital annual reports. However, during the last three years, the use of the Internet by companies in South Africa has shown rapid growth. Most of the companies in South Africa are currently at stage two of the development stages of annual reports on the Internet as identified by Hedlin (1999:73). At this intermediate stage, the companies have a Web presence and an electronic version of the annual report, but are not making use of the interactive features. South African companies should take advantage of the unique interactive nature and multimedia features of Internet technology as a medium to maximize global access to corporate data and information transparency. Companies in South Africa will have to make an extra effort to present information in a format relevant to the needs of various sets of stakeholders by customizing access to information and packaging information and data according to the needs and preferences of stakeholders. Corporate home pages are a competitive asset and the prime gateway to any company. The rich sophisticated multimedia environment of text, graphics, images, sound and audio information will be the primary medium for communicating globally with stakeholders in the future.

\section{References}

Amernic, J.H. 1998. Teaching note: Why corporate financial reporting via the Internet can't be the same old thing. [Online]. Available WWW:

http://mgmt.utoronto.ca/ americ/sameold/htm

(Accessed 26 March 2001).

Clackworthy, C. 2000. The value of reporting. Management accounting (March):38-39.

Conosco. 1999. iRelations - effective on-line investor relations. [Online]. Available WWW: http://www.conosco.com

(Accessed 26 March 2001).

Financial Accounting Standards Board. 2000. Business reporting research project (BRRP). Electronic distribution of business reporting information. Steering committee report series. [Online]. Available WWW: http://fasb.org

(Accessed 26 March 2001).

Financial Mail Special Survey. 2000. Top companies: millennium edition. Supplement to 
Financial Mail (30 June).

Hedlin, P. 1999. The Internet as a vehicle for investor relations: the Swedish case. European accounting review 8(2):373-381.

Koreto, R.J. 1997. When the bottom line is on-line. Journal of accountancy 183(3):63-5.

LaRose, J.A. 1997. Company information on the World Wide Web: using corporate Web pages to supplement traditional business resources. Reference librarian 58:27.

Lehrer, J. 2000. Net worth. Print 54(4):86.

Lymer, A. and Tallberg, A. 1997. Corporate reporting and the Internet - survey and commentary on the use of the WWW in corporate reporting in the UK and Finland. [Online]. Available WWW: http://accounting.rutgers.edu/SUMMA/corp/papers/lymereaa.htm (Accessed 14 April 2001).

O’Kelly, C. 2000. Reporting gets personal. [Online]. Available WWW:

http://www.icai.ie/accountancy-ireland/articles/reportinggetspersonal.htm

(Accessed 27 February 2001).

Petravick, S. Online financial reporting. CPA journal 69(2):32-36.

Rhein, J.H.W. 2000. Annual reports: numbers in cyberspace. Equities (Mar/Apr) 48(2):73.

Russel, J. 2000. University trades in pricey annual report, delivers info via the Web instead. New Orleans city business (21 February): 15.

Stainbank, L.J. 2000. The status of financial reporting on the Internet. Accountancy SA (April):23,25.

Toronto Stock Exchange. 1999. Electronic communications disclosure guidelines. [Online]. Available WWW: http://tsers.com

Accessed 26 March 2001).

\section{Disclaimer}

Articles published in SAJIM are the opinions of the authors and do not necessarily reflect the opinion of the Editor, Board, Publisher, Webmaster or the Rand Afrikaans University. The user hereby waives any claim he/she/they may have or acquire against the publisher, its suppliers, licensees and sub licensees and indemnifies all said persons from any claims, lawsuits, proceedings, costs, special, incidental, consequential or indirect damages, including damages for loss of profits, loss of business or downtime arising out of or relating to the user's use of the Website. 
ISSN 1560-683X

Published by InterWord Communications for the Centre for Research in Web-based Applications, Rand Afrikaans University 